\title{
Choanal atresia
}

INSERM

\section{Source}

INSERM. (1999). Orphanet: an online rare disease and orphan drug data base. Choanal atresia. ORPHA:137914

Choanal atresia (CA) is a cong enital anomaly of the posterior nasal airway characterized by the obstruction of one (unilateral) or both (bilateral) choanal aperture(s), with clinical manifestations ranging from acute respiratory distress to chronic nasal obstruction. 